\title{
Realidade Aumentada e Interdisciplinaridade: o Uso do Aplicativo LandscapAR no Ensino de Matemática e no de Geografia
}

Jhonatas Mayke Junkes de Carvalho'*

Tarliz Liao ${ }^{1}$

1 Universidade Tecnológica Federal do Paraná -Av. dos Pioneiros, 3131 Jardim Morumbi, Londrina, PR - Brasil. *geojhon2016@gmail.com

\section{Resumo}

Este artigo é norteado pelos resultados de uma pesquisa que buscou refletir acerca de uma ação didática, com lócus em uma escola pública da rede estadual do Paraná, onde todos os sujeitos eram alunos de ensino médio e pertencentes a uma geração $Z$, que consolida de forma mais eficaz seu aprendizado via tecnologias digitais.O objetivo geral da pesquisa foi verificar se ocorreriam abstrações e se legitimariam apropriações cognitivas em um viés interdisciplinar da Geografia e Matemática, através do aplicativo LandscapAR. Os resultados apontaram para um processo de aprendizagem mais participativo dos alunos na interação com esse aplicativo de realidade aumentada e, na mesma medida, apropriaram-se dos conceitos pretendidos.

Palavras-chave: Ensino de geografia. Educação matemática. Literacia midiática. Realidade aumentada. LandscapAR.

\section{(c) (i)}

Recebido 24/ 05/ 2020 Aceito 24/ 06/2020 Publicado 01/ 07/ 2020

\section{COMO CITAR ESTE ARTIGO}

ABNT: CARVALHO, J. M. J; LIAO,T. Realidade Aumentada e Interdisciplinaridade: o Uso do Aplicativo LandscapAR no Ensino de Matemática e Geografia. EaD em Foco, V10(2):e1049.2020 DOI: https://doi.org/10.18264/eadf.v10i2.1049 


\section{Augmented Reality and Interdisciplinarity: the Use of LandscapAR Application in the Teaching of Mathematics and Geography}

\section{Abstract}

This article is guided by the results of a research that sought to reflect on a didactic action. The methodology used is deployed by means of qualitative research, in the perspective of a case study, with a class in the public school of the Paraná state, where all individuals are high school students and belonging to a generation $Z$, which the general objective of the research was to verify if abstractions occurred and if cognitive appropriations were legitimized, in an interdisciplinary case of Geography and Mathematics, using the application LandscapAR. The results pointed to a more participatory learning process of the students in the interaction with this augmented reality application, and, in the same measure, they appropriated the intended concepts.

Keywords: Geography teaching. Mathematics education. Media literacy. Augmented reality. LandscapAR.

\section{Notas introdutórias}

A teoria do Determinismo Tecnológico (Escola de Toronto) indica que os avanços tecnológicos transformaram a forma com a qual as pessoas se comunicam e se comportam. Tais avanços modificaram a sociedade, hoje chamada de Sociedade da Informação '. Vários segmentos sociais passam por esse interregno, buscando se adaptar, inovar e ressignificar sua forma de atuação frente às atuais demandas (TOURAINE,1998; TOFFLER, 2001; LÉVY,1999; CASTELLS, 2005; SANTAELLA, 2013).

Os avanços tecnológicos alteraram as formas de se comunicar, pensar, criar e interagir das pessoas nos diversos lugares e partes do mundo. A difusão e a evolução da internet trouxeram à sociedade da informação a virtualização da comunicação e o aumento do fluxo de informações no ciberespaço, que, a cada dia, atrai mais adeptos.

No espaço escolar, isso não é diferente, embora caminhe a passos lentos (MORAN, 2014).O desconforto dessa estrutura tradicionalmente conservadora reflete o descompasso entre o modelo social para o qual foi criada e a atual geração de alunos, cada vez mais conectada ao ciberespaço e imersa na cibercultura (GADOTTI, 2003; LÉVY, 1999; PRENSKY, 2001).

Dessa forma, ao considerar todo esse contexto contemporâneo permeado de viés tecnológico, a pesquisa que originou este artigo teve por objetivo principal analisar uma ação didática interdisciplinar. Essa situação de ensino-aprendizagem envolveu o ensino de Geografia e a educação matemática, por meio de um aplicativo de realidade aumentada endereçado à atual geração de alunos "nativos digitais", termo conceituado adiante.

Expostos à cultura digital desde os primeiros anos de vida, a recente geração de alunos nativos digitais, homozapiens ou, ainda, Geração Z (VEEN; VRAKKING, 2009) divide sua atenção entre o mundo real e

1 Neste texto, denominaremos a atual sociedade de Sociedade da Informação (LÉVY, 1999), consoante outras designações, tais como Sociedade em Rede (CASTELLS, 2005), Sociedade da Comunicação, entre outras. 
o virtual. O intenso uso de tecnologias digitais por esse público tem proporcionado alterações cognitivas relacionadas à memorização de informações, aprendizagem e desenvolvimento educacional.

[...] essa potencialidade da tecnologia digital está diretamente ligada a sua capacidade de excitar o indivíduo, gerando uma estimulação dos sistemas auditivo, visual e emocional. Alterando assim, a sua capacidade cognitiva, seja de tom benéfico ou maléfico, dependendo da forma como é utilizada e da intensidade do seu uso (HOOGEVEEN, 1997 apud SILVA, 2017, p.293).

Sobre a relação e coexistência de diferentes gerações no ambiente escolar, Prensky $(2001$, p.1) afirma que "os alunos mudaram radicalmente, os alunos de hoje não são os mesmos para os quais o sistema educacional foi criado". Ainda de acordo com Prensky (2001), os imigrantes digitais são indivíduos/docentes que cresceram nas décadas anteriores a 1980. Esses tiveram relação tardia com as TD, apresentam certa insegurança ao usar dispositivos e recursos tecnológicos aplicados à educação, embora sejam capazes de se apropriar e de aprender a linguagem, obtendo sabedoria digital (PRENSKY, 2012).

Kucharski (2019) segue indicando que a "Geração Z" encontra-se imersa nas tecnologias digitais, em função de entender como baixá-las, instalá-las e usá-las. Ela tem, inclusive, ensinado aqueles que nasceram em gerações anteriores. Para a Geração Z, “o critério principal para adotar a tecnologia não é o fato de o software ou programa ter boa usabilidade, mas o fato de dar conta ou não de suas exigências e necessidades." (VEEN; VRAKKING, 2009, p. 17).

Frisamos que, neste texto, iremos considerar que o termo nativo digital não se associa à simples relação das tecnologias digitais com faixas etárias. Há diversos fatores envolvidos, como, por exemplo, classe econômica e características culturais.

A adoção de metodologias híbridas de ensino num contexto de crise e transição de paradigmas parece ser o caminho a ser trilhado. Isso para oportunizar uma aprendizagem interdisciplinar, significativa, criativa, interativa, engajada, colaborativa e mediada por tecnologias digitais de informação e comunicação (TDIC). Seguindo essa concepção, o ensino de Geografia, na Educação Básica, busca esclarecer o aluno sobre as relações estabelecidas entre sociedade e Natureza, em diferentes escalas de abordagem ao longo do tempo-espaço. Por sua vez, a educação matemática busca nortear o entendimento da mesma para o exercício da cidadania e para compreender os construtos matemáticos como herança cultural e científica.

Utilizada de maneira racional e direcionada para fins educacionais, a tecnologia digital facilita a aquisição de informações em diferentes mídias, como também aproxima o aluno nativo digital de seu contexto. Faz isso ao estimular suas habilidades e capacidades de adaptação a ambientes que requerem competências informáticas e tecnológicas para a construção do conhecimento (PEREIRA et. al., 2018; SILVA,2017).

Fadel (2020), em seu trabalho de conclusão de curso, intitulado "A realidade aumentada aplicada à Geografia: levantamento bibliográfico em repositórios digitais", apresenta uma lista dos repositórios brasileiros de acesso aberto, onde catalogou todas as publicações que pesquisavam realidade aumentada em temas correlatos à Geografia. Constatou que esse número ainda é tímido e que as TD têm capacidade de promover maiores e melhores apropriações cognitivas no campo da Geografia.

Nessa direção, uma ação didático-pedagógica interdisciplinar, com o uso de recursos digitais e mídias locativas por meio da tecnologia e, em especial, por meio da realidade aumentada, parece contribuir para o que tem sido desenvolvido. 


\section{Realidade aumentada e o LandscapAR}

A realidade aumentada é um recurso inovador com grande potencial para sanar as dificuldades de abstração do aluno, uma vez que possibilita manipular e simular a visualização de objetos virtuais tridimensionais integrados à sua percepção sensorial do ambiente real. Com isso, torna possível a imersão e interação do aluno de maneira natural, ao passo que o aproxima de seus hábitos cotidianos.

Segundo Kirner (2011), a realidade aumentada permite a mistura de objetos reais e virtuais no espaço físico do usuário. A interação é em tempo real, por meio das informações geradas pelo computador em 3D e visualizadas através de dispositivos tecnológicos, como smartphones. Em relação às diferenças entre realidade virtual e realidade aumentada, o autor discorre que:

Diferentemente da realidade virtual, que procura transportar o usuário para o ambiente virtual, a realidade aumentada mantém o usuário no seu ambiente físico e transporta o ambiente virtual para o espaço do usuário, por meio de algum dispositivo tecnológico. Assim, a interação do usuário com os elementos virtuais ocorre de maneira natural e intuitiva, sem necessidade de adaptação ou treinamento. (KIRNER; KIRNER, 2011 p.16).

Na esteira de realidades ubíquas, de tecnologias em sala de aula, a Geografia também busca estar inserida. Esta, que descreve, explica e relaciona as interações existentes entre a sociedade e a Natureza ao longo do tempo e do espaço, utiliza-se de inúmeros artefatos digitais para tornar-se mais atrativa. Na carona da ação proposta, de forma natural e contextualizada, buscamos explicitar conceitos geométricos de Matemática permeados em outras áreas e espaços, bem como promover e aprofundar a discussão sobre abstração.

Corroborando com os próprios conceitos da Geografia, que estuda as relações entre homem-Natureza, homem-homem e homem-máquina, estabelecidas ao longo do tempo, os objetos evidenciam as características peculiares de cada momento histórico e configuram arranjos espaciais e sociais que refletem as técnicas e tecnologias empregadas em seu modo de ser, agir e pensar.

A realidade virtual possibilita abstrações visuais quanto à noção de espaço, tanto para Geografia quanto para Matemática. Aplicada à primeira, permite ao aluno ultrapassar as fronteiras do espaço físico; quanto aplicada à segunda, permite a visualização da extensibilidade do infinito de uma reta.

A imersão no ambiente virtual permite que o aluno tenha uma experiência multissensorial similar, como se estivesse fisicamente no local, em aula de campo. Apesar dos benefícios da aprendizagem empírica in loco, ressalta-se que esta pode ser excludente ao esbarrar nas limitações de mobilidade e/ou fobias, podendo até mesmo trazer riscos à integridade física do aluno. Isso sem contar a miríade de possíveis imprevistos, como intempéries e custos com organização e transporte. Tais percalços são controlados em ambientes de realidade virtual, favorecendo vivência em um espaço distante ou de difícil acesso, havendo, dessa forma, maior inclusão.

Pesquisas no ensino de Geografia (PINTO; CENTENO, 2012; SILVA et.al., 2014) indicam que o uso de interfaces de RA com conotação geográfica possibilita a geração de um ambiente de aprendizagem engajado, interativo, criativo e colaborativo, em que a autonomia e o protagonismo dos estudantes são estimulados a partir da projeção e mistura de elementos virtuais e reais em um contexto social imersivo. E ainda possibilita entender de que forma a Matemática se insere na perspectiva geométrica de mensuração de áreas, de localização terrestre/espacial e, o indispensável, utilizar o bom senso para adaptar medidas da Matemática à realidade cotidiana. 
Dessa forma, conforme mencionado anteriormente, este artigo detém-se em uma ação didática interdisciplinar promovida por meio de um aplicativo de realidade aumentada, chamado LandscapAR (WEEKEND, 2018).

O LandscapAR configura-se como um recurso digital com grande potencial a ser explorado pela disciplina de Geografia e educação matemática na conjugação com a primeira. Esse aplicativo de realidade aumentada possibilita explorar, associar e integrar informações, temáticas e conceitos que envolvem cartografia, geomorfologia, hidrografia e orientação espacial, geometria espacial, plana e esférica. Reconhece as curvas de nível desenhadas na folha de papel (conceito esse também trabalhado em Matemática como topologia), e através da câmera do smartphone projeta um perfil topográfico virtual, sendo possível identificar as diferenças altimétricas das porções mais baixas e elevadas da superfície. Com isso, é possível observar também as diferentes formas de relevo, como cadeias montanhosas, planícies, planaltos e suas variações (cordilheira, vale, morro, escarpa, planície litorânea, entre outras), feições geomorfológicas costeiras, como enseada, baía, cabo, golfo, fiordes, istmo e, além disso, pode-se observar o que em Matemática foi exemplificado e inferido como gráfico de funções de várias variáveis (CHRISTOFOLETTI, 1980; PENTEADO,1983).

Esse aplicativo apresenta muitas possibilidades pedagógicas; entre elas, estão o estudo de percepção e leitura espacial, os conceitos geográficos sobre as formas de relevo, a geometria de áreas planas e curvas, a paisagem, a altitude, o perfil topográfico, as curvas de nível em mapas e cartogramas. A percepção e leitura espacial das formas do relevo em mapas é uma tarefa abstrata e pouco atraente para muitos alunos da Educação Básica, haja vista a dificuldade de observar as curvas de nível no cartograma e imaginar/ projetar seus contornos e formas de relevo na realidade.

Um refletir interdisciplinar é capaz de confluenciar conceitos de áreas distintas. Assim, o viés da educação matemática acerca dos conceitos geográficos anteriores norteia o aluno para que:

[...] possa perceber seu entorno espacial para além daquilo que se consegue ver fisicamente, mas não somente imerso nos processos de abstração em geometria, e ainda, objetiva-se ter-se a compreensão de que nem todos os traçados e medidas são lineares, demarcados pela geometria euclidiana. Há ainda a perspectiva da apropriação do conceito de território e territorialidade necessário ao viés sociopolítico que se busca imprimir [...]. (LIAO et. al., 2020, p.177).

A aprendizagem mediada por esse aplicativo permite ao aluno superar suas limitações de abstração e imaginação ao receber estímulos multissensoriais das informações representadas em 3D - conceito matemático de espaço, geralmente representado numa lousa através dos eixos x, y e z, descolado da representação espacial de um ambiente natural. Isso favorece e dá espaço à criatividade, ao propiciar a manipulação e simulação de cenários passíveis de serem explorados em estratégias de ensino de Geografia, tais como processos naturais (fenômenos e peculiaridades do clima, relevo, solo, vegetação e hidrografia), apropriação e uso do solo (áreas urbanizadas e/ou industrializadas, agrícolas, de extração/ exploração mineral e vegetal, pontos turísticos, dentre outros). Há ainda a possibilidade de trabalhar outros conceitos matemáticos, como proporcionalidade, medidas de capacidade, razão nas discussões de irrigação, plantação, colheita, entre outros.

A reconceituação de medição [...] por vezes, é tarefa árdua de realizar, uma vez que, ao desconstruir um paradigma imposto oficial e necessariamente, subjaz um repensar de especificidades regionais, na diversidade de unidades de comprimento, área e volume. Entretanto, esse intento segue além, quando este conceito não foi tecido de forma a sustentar o conceito fundamental de forma [...] (AUTOR et.al., 2020, p.185) 
As imagens tridimensionais, visualizadas na tela do smartphone pelo aplicativo, são geradas com o auxílio da câmera do aparelho, a partir do escaneamento, captura e reconhecimento das curvas de nível desenhadas em uma folha de papel (Figura 1).

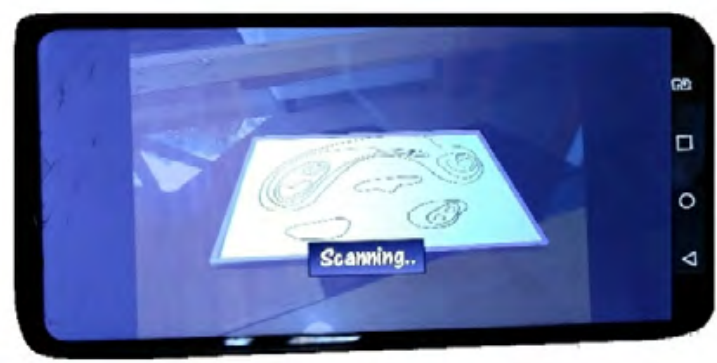

Figura 1: Escaneamento das curvas de nível via LandscapAR Fonte: Os autores (2019).

Para que esse processo ocorra de maneira satisfatória, as linhas que representam as curvas de nível devem ser traçadas em papel claro, com a utilização de canetinha preta de ponta espessa, sem que ocorra a sobreposição das linhas (Figura 2). A fim de facilitar o escaneamento, o papel deve ser claramente visível a partir de um plano de fundo escuro (WEEKEND, 2018).

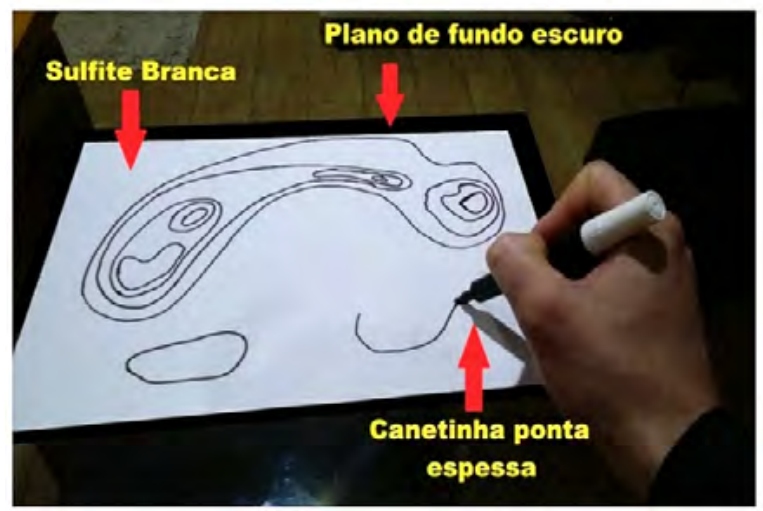

Figura 2: Reconhecimento e escaneamento via LandscapAR Fonte: O autor (2019)

Após escaneamento e captura da imagem através dos marcadores (código previamente reconhecido pelo software), obtêm-se as curvas de nível. O programa gera uma projeção virtual 3D (Figura 3), representada por um perfil topográfico, com grande riqueza de detalhes (ilhas, formas da superfície, sombreamento e aparente movimento da superfície líquida), permitindo ao usuário superar sua dificuldade de imaginação e abstração sobre como seriam as formas da superfície na realidade, a partir da interpretação das curvas de nível (CARDOSO, 2014 p.332 apud RESENDE et. al., 2016). 


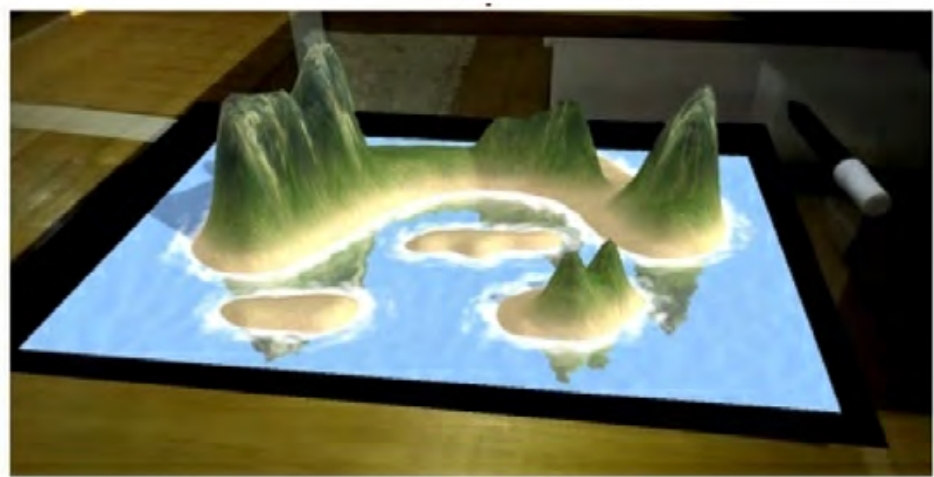

Figura 3: Imagem projetada em 3D viaLandscapAR Fonte: O autor (2019).

A partir do contorno das curvas de nível, são geradas e projetadas imagens tridimensionais que representam cenários de grandes e pequenas ilhas, proporcionando a imersão parcial do aluno ao visualizar objetos virtuais sobrepostos à carteira e ao espaço físico da sala de aula. Isso favorece as formas da superfície/relevo a partir da leitura das curvas de nível em uma folha de papel. Ademais, a imagem gerada pelo aplicativo possibilita a interatividade do aluno em diferentes perspectivas (Figura4).
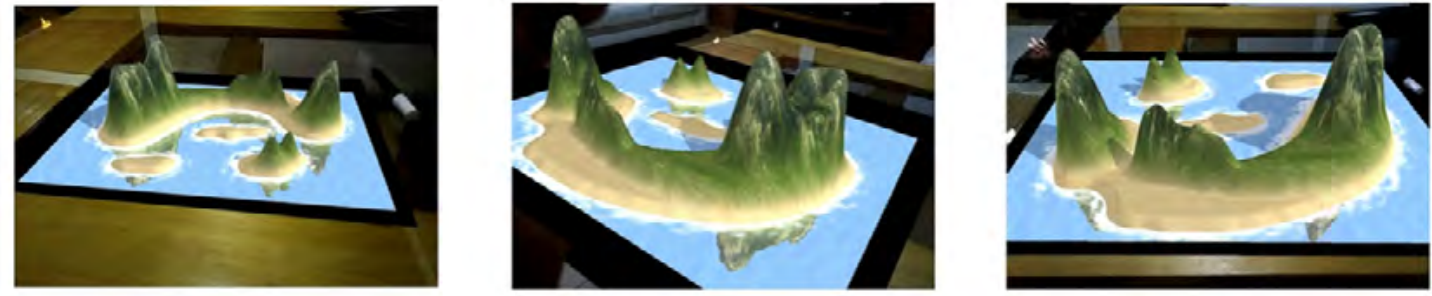

Figura 4: Diferentes perspectivas em 3D

Fonte: $O$ autor (2019).

AUTOR et. al. (2020), em sua proposta interdisciplinar entre Geografia e educação matemática, também alertam sobre o conceito de perímetro trabalhado em salas de aula. A apresentação desse conceito, geralmente, é pautado por pequenos objetos, quando, na realidade, é possível "mensurar" áreas e perímetros através do Google Earth com boa precisão e de forma que o conceito de área torne-se mais significativo.

Após projeção da imagem 3D, o software oferece a possibilidade de o usuário salvar e/ ou compartilhar o arquivo no menu de compartilhamento do software, representado por um ícone de câmera no lado direito do visor. Nesse ícone, estão disponíveis as opções de 1) salvar no diretório LandscapAr.imagens, criado ao baixar o aplicativo na memória interna do smartphone; 2) compartilhar ao clicar no ícone de compartilhamento universal, no qual se abrem múltiplos canais; 3) compartilhar diretamente a partir do ícone do Facebook, disponível no menu do software (Figura 5). 


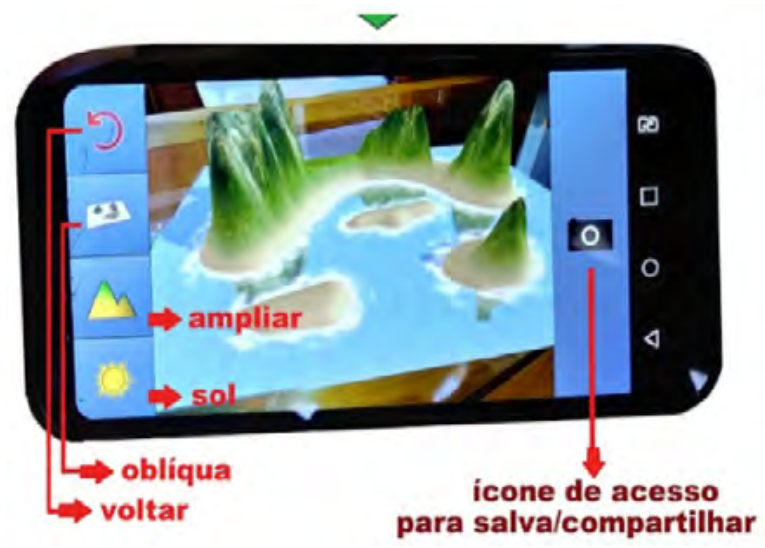

Figura 5: Armazenamento e compartilhamentos via LandscapAR

Fonte: O autor (2019).

\section{Métodos e ação didática}

A pesquisa que originou este texto é de cunho qualitativo, inserida em uma abordagem por meio de estudo de caso, em que fora realizada uma ação didática com alunos do $1^{\circ}$ ano do Ensino Médio de uma escola da rede estadual do Paraná.

Alves e Silva (1992, p.1) indicam que "A análise qualitativa de dados é um fenômeno recentemente retomado, que se caracteriza por ser um processo indutivo que tem como foco a fidelidade ao universo de vida cotidiano dos sujeitos". Essa ideia é complementada por André (1983), quando diz que "ela visa apreender o caráter multidimensional dos fenômenos em sua manifestação natural, bem como captar os diferentes significados de uma experiência vivida, auxiliando a compreensão do indivíduo no seu contexto" (p.45).

Reiteramos ainda que passos metodológicos em uma abordagem qualitativa não se constituem propostos em medida prescritiva. O pesquisador não deve levar em conta apenas a sua intuição, tal qual um sujeito isolado; há que considerar o contato com a realidade investigada, relacionado aos pressupostos teóricos que sustentam seu projeto. Assim, ao recusar a inflexibilidade, o pesquisador não deverá perder a exatidão em seu trabalho, condição sine qua non para a materialização de um projeto científico que possa vir a contribuir para um conhecimento na área.

Portanto, ao pretender realizar uma análise qualitativa seria fundamental verificar como deveria ocorrer a coleta de dados, mais especificamente, que formato de entrevista seria o mais pertinente [...]os estudos encaminham preferentemente para propostas de entrevistas definidas por Cannel e Kahn (1974) como semiestruturadas, que pedem uma composição de roteiro com tópicos gerais selecionados e elaborados de tal forma a serem abordados com todos os entrevistados. (ALVES; SILVA, 1992, p.1).

Dessa forma, condutas de aproximação, como empatia e respeito a partir de atitudes do pesquisador, é que reverberam a fluidez dos sujeitos e o seu compromisso enquanto informantes. Isso acarreta a validação dos dados coletados - o que propicia um momento de retomada de fatos, valores, reflexão e posturas anteriores. 
Fernandes (1991) argumenta que o pesquisador, quando em uma entrevista via relato oral, consolida vínculo com os entrevistados e que:

[...] longe de se constituir em tarefa atribuída a debutantes, ela concretiza o lugar privilegiado onde se articulam conhecimento livresco e realidade espontânea, princípios universais e o singular concreto, conceptualização formalista e intuição pessoal. E, sobretudo obriga o pesquisador a se interrogar sobre si próprio e suas motivações para poder questionar os outros. (FERNANDES, 1991, p.10).

Dessa forma, a análise qualitativa se qualifica no processo de apreensão de significados no discurso dos sujeitos, articulada ao contexto em que eles estão inseridos e delimitada pelas concepções teóricas do pesquisador. Ele leva em conta, na concepção de seu texto, uma sistematização norteada na qualidade, residindo no fato de que um trabalho dessa natureza não pretende atingir o limiar da representatividade (FERNANDES, 1991).

A ação didático-pedagógica que tratou da utilização do aplicativo LandscapAR foi elaborada e promovida junto a um grupo de alunos da rede estadual de ensino público. Ocorreu no mês de março e início de abril de 2019, com 50 alunos na faixa etária de 15 a 17 anos, cursando o $1^{\circ}$ ano do Ensino Médio no período noturno.

A escolha desses sujeitos deveu-se ao fato de que, desde a infância, a maioria desses indivíduos está em contato e sob influência das tecnologias digitais, geração Z. No entanto, poucos as utilizam em atividades escolares a favor de suas apropriações cognitivas e ao desenvolvimento de uma aprendizagem significativa, algo que lhes permitiria um melhor exercício da cidadania e lhes permitiria compor, de forma ativa e criativa, uma nova sociedade.

O estabelecimento de ensino atende alunos das séries iniciais do Ensino Fundamental II ao Ensino Médio. A estrutura física é precária, com algumas salas de madeira, ausência de laboratório, parque tecnológico insuficiente e/ou defasado. A maior parte dos alunos do colégio apresenta núcleo familiar relativamente estruturado, com pais que terminaram o Ensino Médio e que possuem extensa jornada de trabalho ao longo da semana. Enquadram-se no perfil de renda das classes sociais D e E (IBGE, 2019).

Essa ação oportunizou a aprendizagem dos alunos tanto no espaço virtual como no espaço físico da sala de aula tradicional, por meio de uma atividade viabilizada por tecnologias digitais. Para a efetivação dessa proposta híbrida de ensino, com o uso da web, dispositivos móveis, utilização dos aplicativos LandscapAR, Whatsapp e mediação do professor, fez-se necessário que o docente programasse quatro horas-aula de 45 minutos cada uma, em sala de aula, sem contar o tempo de estudo independentemente dos alunos para pesquisa, compartilhamento de informações, produção e entrega do relatório final.

Nesse ponto, iremos discorrer sobre o desenvolvimento da ação que consistiu basicamente em três etapas descritas a seguir:

$1^{\text {a }}$ etapa) Os alunos receberam orientações sobre o nome do aplicativo a ser baixado em seus dispositivos móveis e dos materiais a serem utilizados. Tomaram ciência dos temas a serem pesquisados (altitude, perfil topográfico, escala, curvas de nível e formas do relevo); de como seriam avaliados; e receberam um modelo de relatório a ser entregue em PDF, via aplicativo WhatsApp de maneira individual;

$2^{a}$ etapa) Aula expositiva dialogada, interação e feedback entre professor e alunos sobre os conceitosbase, geográficos e matemáticos. Nessa etapa, o professor organizou os temas da pesquisa em slides, pontuando os conceitos-chave. Os alunos puderam organizar-se em grupos de três, permitindo com que 
a aprendizagem fosse oportunizada, apropriando-se dos temas e conceitos que deveriam ser discutidos e compartilhados;

$3^{a}$ etapa) Nesta etapa, os alunos aprenderam praticando. Com os materiais em mãos, teve início o processo de desenho das curvas de nível na folha de papel sulfite e discussão de conceitos que se buscava trabalhar. Em seguida, realizou-se o registro do passo a passo por meio de fotos, seguindo para o uso do aplicativo.

\section{Resultados e discussões}

Constatou-se o relevante afinco dos alunos na atividade desenvolvida pelo fato de tratar-se de atividade operada por tecnologia digital e, ainda, por contado protagonismo de sua aprendizagem ao longo dessa proposta. Cabe ressaltar o compartilhar de ideias, dificuldades e limitações quanto ao envolvimento com literácia midiática e sabedoria digital.

Quanto ao processo avaliativo dos alunos, optou-se pelo instrumento processual que considerou o envolvimento e desenvolvimento do aluno em cada etapa. Assim, esse relatório final nos possibilitou verificar a aprendizagem mediada por tecnologia digital, aproximando e oportunizando o exercício das habilidades de literácia midiática do aluno, ou mesmo favorecendo sua inclusão digital, o que contou, ainda, com a apropriação de conhecimentos geográficos e da Matemática.

O fato de nem todos os alunos possuírem smartphone android e os aplicativos instalados não inviabilizou a aplicação da ação didática. Isso porque, nesse momento, a cooperação entre os alunos foi estimulada. Ajudavam, ensinavam e mostravam suas descobertas uns aos outros, compartilhando informações, intensificando a interação de maneira interativa, criativa e divertida.

Efetivada a etapa de uso do LandscapAR e da coleta e armazenamento de dados, iniciou-se a fase de término do relatório. $O$ destaque nesse momento da atividade foi a atuação dos alunos no grupo de trabalho criado no WhatsApp. O volume de mensagens trocadas entre os alunos aumentou, o protagonismo e a forma colaborativa de compartilhar informações de alguns alunos se destacaram.

Intervenções ocorreram apenas em situações de propagação de informações equivocadas, ou quando surgiu algo que o grupo de trabalho não conseguiu resolver. Próximo à data-limite, de entrega da atividade, os trabalhos foram gradativamente postados via aplicativo, o que promoveu mais interação entre os alunos no grupo de discussão. A interação deveu-se a entrar em contato com as produções dos colegas à medida que eram postados os relatórios, o que serviu de espelho para aqueles que ainda não haviam finalizado sua produção.

Em nível cognitivo, foi possível observar a apropriação tanto dos conceitos geográficos quanto dos da Matemática que buscaram ser trabalhados, uma vez que, nos encontros subsequentes, ocorreu uma "retomada" dos tópicos ministrados anteriormente.

\section{Considerações Finais}

Este texto apresenta um ponto final; entretanto, é paradoxalmente continuativo, no sentido de que novos artefatos e concepções tecnológicas poderão compor novos cenários para a apropriação de conceitos da Geografia por meio de uma aproximação com a educação matemática, no que tange à sua perspectiva de discussões de caráter social, humano e de espaço.

As inovações tecnológicas transformaram o modo de ser, agir e pensar dos indivíduos nesta Sociedade da Informação e, por consequência, a vida social real e virtual. Aprender e ensinar em um contexto 
tecnológico, em que a informação é ubíqua, torna-se a cada dia uma tarefa mais desafiadora. Ela exige compreender as demandas educacionais da atual geração de alunos "nativa digital", que confronta o modelo tradicional de ensino, perpetuado por décadas; ensinar e aprender a aprender, como também produzir, por meio de recursos tecnológicos e na linguagem digital, sem propagar a falsa impressão de saber; e ser capaz de oportunizar uma aprendizagem contextualizada, criativa e significativa, mediada por tecnologias digitais de informação e comunicação.

Dessa forma, docentes devem refletir a respeito dos mesmos conceitos trabalhados em diversas áreas do conhecimento, ensinado sob diferentes ópticas, como se fossem elementos distintos entre si. Nesse sentido, conceitos e operações matemáticas ganhariam mais significado, não se descolando de uma realidade mais palpável, tão justamente reclamada por alunos que não atribuem sentido àquilo que aprendem.

Neste artigo, buscamos evidenciar que as inovações tecnológicas criaram novas demandas educacionais mais próximas ao cotidiano e de legitimação do conhecimento, à facilidade de acesso à informação, às formas de comunicação e ao comportamento da atual geração de alunos, que afetam diretamente as relações de ensino-aprendizagem. Exigem a adoção de novas condutas pedagógicas. Essas devem ser contextualizadas, ativas, criativas, colaborativas, compatíveis com a atual geração de alunos que, ao contrário do que se perpetua no senso comum, não possui conhecimento digital intrínseco ou mesmo sabedoria digital congênita. Necessitam aprender a aprender e produzir na linguagem digital, exercitar e ampliar seu envolvimento com a literácia midiática.

Nesse âmbito, a ação didática traz uma proposta interdisciplinar de ensino que considera o contexto tecnológico, explora o espaço híbrido de ensino, compreende que o acesso à informação e à aprendizagem pode ocorrer em qualquer tempo e espaço, utiliza as mídias locativas dos alunos e oportuniza o ensino de temáticas e conceitos da Geografia, aproximando-os de conceitos da Matemática, a partir do uso de recursos digitais, web e do aplicativo LandscapAR.

Oportunizar situações de ensino-aprendizagem ativas e integradas a uma abordagem tecnológica digital, com o auxílio de recursos digitais disponíveis e acessíveis, aproxima o aluno de seu contexto tecnológico, social e cultural; estimula seu protagonismo e torna o processo de ensino-aprendizagem mais significativo - fato esse presenciado ao longo da aplicação da ação didático-pedagógica. Ela facilitou o acesso aos sujeitos-alunos que, por sua vez, se envolveram com a situação de aprendizagem e fizeram uso da tecnologia de realidade aumentada para aprender, divertir-se, colaborar e compartilhar informações sobre conteúdos de Geografia.

A estratégia de ensino facilitou o processo de abstração e imaginação dos alunos sobre as formas de relevo e conceito de área e volume, a partir do uso do aplicativo LandscapAR. Para além da visualização de objetos virtuais posicionados no ambiente da sala de aula, a situação de ensino-aprendizagem permitiu inserir e explorar os conteúdos sobre percepção espacial, paisagem, altitude, perfil topográfico, curvas de nível e escala cartográfica, pois a proposta despertou o interesse dos alunos e os deixou acessíveis - elemento que contribuiu sobremaneira para suas apropriações cognitivas.

Sobre o aplicativo LandscapAR, a pesquisa demonstrou sua vocação pedagógica para o ensino de Geografia e apresentou algumas limitações, como a ausência de representação de áreas deprimidas e a indisponibilidade em dispositivos IOS. Acredita-se que, a partir dessa pesquisa, novas situações de ensino-aprendizagem possam ser criadas e exploradas com o uso do aplicativo mencionado, como também este ser aplicado a outros níveis de ensino e áreas do conhecimento.

Também é válido ressaltar que os resultados dessa ação evidenciam possibilidades de futuros estudos voltados ao desenvolvimento de aplicativos de realidade aumentada correlacionados à temática explorada pelo LandscapAR. Isso, visto que suas limitações podem servir de estímulo para a criação de novos 
recursos educacionais digitais, com novas funções que agreguem valor e possam ser aproveitadas para o ensino de Geografia.

Contudo, espera-se que este tenha contribuído para a formação docente, estimulando novas situações de ensino-aprendizagem mediadas por TDIC e promovendo condutas pedagógicas apropriadas à atual geração de alunos.

\section{Referências}

ALVES, Z. M. M. B.; SILVA, M. H. D. Análise qualitativa de dados de entrevista: uma proposta. Paidéia. Ribeirão Preto. 1992. Disponível em: <https://www.scielo.br/scielo.php?script=sci_arttext\&pid=S0103-863X1992000200007>. Acesso em: 31 jan.2020.

ANDRÉ, M. E. D. A. Texto, contexto e significado: algumas questões na análise de dados qualitativos. Cadernos de Pesquisa.1983

CARDOSO, R. G.S.; PEREIRA, S. T.; CRUZ, J. H. M.; ALMEIDA, W. R. M. Uso da realidade aumentada em auxílio à educação. Computer on the Beach. São Luiz. MA. p.330-339. 2014. Disponível em: <https:// siaiap32.univali.br/seer/index.php/acotb/article/view/5337>. Acesso em: 28 maio 2019.

CASTELLS, M.; CARDOSO, G.. A Sociedade em Rede do Conhecimento à Acção Política. Centro Cultural de Belém, Belém, 2005. Disponível em: <https://cienciastecnologiassociedades.files.wordpress. com/2011/11/sociedade-em-rede-manuel-castells-gustavo-cardoso-org.pdf>. Acesso em: 23 maio 2019.

CHRISTOFOLETTI, A. Geomorfologia. 2. ed. São Paulo: Edgard Blücher, 1980.

FADEL, J. E. A realidade aumentada aplicada na Geografia: levantamento bibliográfico em repositórios digitais. 2020. Trabalho de Conclusão de Curso (Especialização em Inovação e Tecnologias na Educação). Universidade Tecnológica Federal do Paraná. Curitiba. 2020.

FERNANDES, M. E. Memória camponesa. Em, M.A. Matos; D.G. Souza; R. Gorayeb e V.R.L. Otero (Orgs.) Anais da XXI Reunião Anual de Psicologia. Ribeirão Preto: Sociedade Brasileira de Psicologia. 1992.

GADOTTI, M. História das idéias pedagógicas. São Paulo: Editora Ática, 2003. Disponível em: < $\underline{\text { http:// }}$ acervo.paulofreire.org:8080/xmlui/handle/7891/2787>. Acesso em: 10 maio 2019.

IBGE - Instituto Brasileiro de Geografia e Estatística. IBGE divulga o rendimento domiciliar per capita 2018. Agência de notícias IBGE, Estatísticas sociais, Brasil, fev. 2019. Disponível em: <https://agenciadenoticias.ibge.gov.br/agencia-sala-de-imprensa/2013-agencia-de-noticias/releases/23852-ibge-divulga-o-rendimento-domiciliar-per-capita-2018>. Acesso em: 05 jun. 2019.

KUCHARSKI, M. V. S. Fundamentos de Inovação e Tecnologia na Educação. Especialização em Inovação e Tecnologias na Educação (INTEDUC). Universidade Tecnológica Federal (UTFPR). 2019.

KIRNER, C.; KIRNER, T. G. Evolução e Tendências da Realidade Virtual e da Realidade Aumentada. In: SYMPOSIUM ON VIRTUAL REALITY AND AUGMENTED REALITY, 13., 2011, Uberlândia-MG. Realidade Virtual e Aumentada: Aplicações e Tendências. Uberlândia, MG: SBC, 2011. cap. 01, p. 10-25. Disponível em: <http://www.de.ufpb.br/ labteve/publi/2011 svrps.pdf>. Acesso em: 28 maio 2019.

LÉVY, P. Cibercultura. São Paulo: Editora 34. 1999.

LIAO, T.; SANTOS, S.A.; DUARTE, C. G. Educação Matemática: O Google Earth na Percepção Geoespacial. In: MOTTA, Marcelo Souza. CAMARGO, Iolanda Camargo; KUCHARSKI, Marcus Vinícius Santos. (Org). Tecnologias na Educação: Aprendizagem, Ensino e Inovação. $1^{\text {a }}$ edição. Ed. UTFPR. Curitiba. p. 176-194. 2020. 
MORAN, J. M. Uma lenta evolução. [Entrevista concedida a] Gabriel Jareta. Guia de Educação a Distância, São Paulo. p. 8-10, 2014. Disponível em: <http://www2.eca.usp.br/moran/wp-content/uploads/2013/12/evolucao.pdf>. Acesso em: 10 maio 2019.

PENTEADO, M. M. Fundamentos de geomorfologia. 3. ed. Rio de Janeiro: IBGE, 1983. Disponível em: <https://biblioteca.ibge.gov.br/visualizacao/livros/liv81427.pdf>. Acesso em: 30 maio 2019.

PEREIRA, F. C.; AZEVEDO, D. P. G. D.; ALMEIDA, A. S.; FELíCIO, C. B.; RISSE, L. S.; MOREIRA, L. B. Funções cognitivas e os impactos das tecnologias digitais na memória. Temas em saúde, João Pessoa, v. 18, n. 4, 2018. Disponível em: <http://temasemsaude.com/wp-content/uploads/2018/12/18412.pdf>. Acesso em: 01 jul. 2019.

PINTO, F. S.; CENTENO, J. A. S. A realidade aumentada em smartphones na exploração de informações estatísicas e cartográficas. Boletim de Ciências Geodésicas, Curitiba, v.18, n.2, p. 282-301, Abr./Jun. 2012. Disponível em: <https://revistas.ufpr.br/bcg/article/view/27856/18444>. Acesso em: 31 jan. 2020.

PRENSKY, M. Digital Natives, Digital Immigrants. OntheHorizon, Bradford. v. 9. n. 5. p. 2-6, out. 2001. Disponível em: <http://poetadasmoreninhas.pbworks.com/w/file/fetch/60222961/Prensky\%20-\%20 Imigrantes\%20e\%20nativos\%20digitais.pdf>. Acesso em: 15 maio 2019.

PRENSKY, M. Aprendizagem Baseada em Jogos Digitais. São Paulo: Senac-SP. 2012.

RESENDE, V. Literacia midiática: Breve panorama sobre os estudos no Brasil. São Paulo: COMUNICON, 2016. Disponível em: http://anais-comunicon2016.espm.br/GTs/GTPOS/GT8/GT08-VITOR RESENDE. pdf. Acesso em: 20 maio 2019.

SANTAELLA, L. Comunicação ubíqua: repercussões na cultura e na educação. São Paulo: Paulus. 2013.

SILVA, M.; VILAR, E.; REIS, G.; LIMA, J. P.. AR Jigsaw Puzzle: Potencialidades de Uso da Realidade Aumentada no Ensino de Geografia. In: Congresso Brasileiro de Informática na Educação. Recife. Pernambuco. p. 194-203. Disponível em: <https://br-ie.org/pub/index.php/sbie/article/view/2945>. Acesso em: 20 jun. 2020

SILVA, T. O.; SILVA, L. T. G. Os impactos sociais, cognitivos e afetivos sobre a geração de adolescentes conectados às tecnologias digitais. Revista de psicopedagogia, São Paulo, v. 34, n. 103, p. 87-97, 2017. Disponível em <http://pepsic.bvsalud.org/scielo.php?script=sci arttext\&pi$\mathrm{d}=$ =S0103-84862017000100009\&lng=pt\&nrm=iso>. Acesso em: 29 jun 2019.

TOFFLER, A. A terceira onda. São Paulo: Record, 2001.

TOURAINE, A. Poderemos Viver Juntos? Iguais e Diferentes. Petrópolis: Editora Vozes, 1998.

VEEN, W.; VRAKKING, B. Homo zappiens: educando na era digital. Porto Alegre: Artmed, 2009.

WEEKEND, Labs UG. LandscapAR. versão 1,5. Berlin (Alemanha). Jul. 2018. Disponível em: < $<$ ttps://play. google.com/store/apps/details?id=de.berlin.reality.augmented.landscapar> Acesso em: 30 maio 2019. 